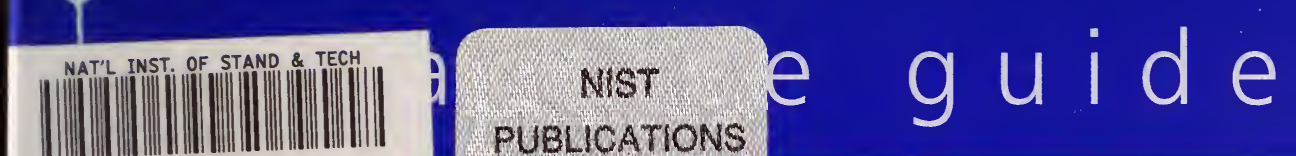

\title{
All106 823600
}

\section{Test Procedures for Developing Solder Data}

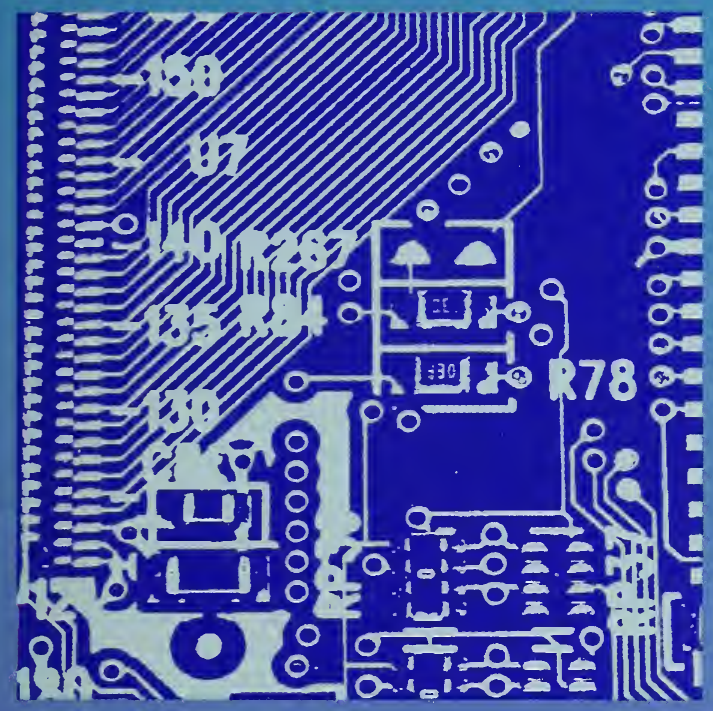

\section{T.A. Siewert}

C.A. Handwerker

QC 100 457 4. 960.8 2002 C. 2

\section{NGT}

National Institute of

Standards and Technology

Technology Administration

U.S. Department of Commerce
Special

Publication 960-8 



\section{NIST Recommended Practice Guide}

Special Publication 960-8

\section{Test Procedures \\ for Developing \\ Solder Data}

NEMI Task Group on

Lead-Free Alloys and

Reliability

Edited by T.A. Siewert and C.A. Handwerker

Materials Science and

Engineering Laboratory

August 2002

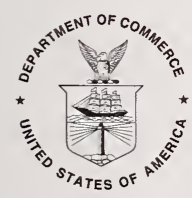

U.S. Department of Commerce Donald L. Evans, Secretary

Technology Administration

Phillip J. Bond, Under Secretary for Technology 
Certain commercial entities, equipment, or materials may be identified in this document in order to describe an experimental procedure or concept adequately. Such identification is not intended to imply recommendation or endorsement by the National Institute of Standards and Technology, nor is it intended to imply that the entities, materials, or equipment are necessarily the best available for the purpose.

National Institute of Standards and Technology Special Publication 960-8

Natl. Inst. Stand. Technol.

Spec. Publ. 960-8

40 pages (August 2002)

CODEN: NSPUE2

U.S. GOVERNMENT PRINTING OFFICE WASHINGTON: 2003

For sale by the Superintendent of Documents

U.S. Government Printing Office

Internet: bookstore.gpo.gov Phone: (202) 512-1800 Fax: (202) 512-2250

Mail: Stop SSOP, Washington, DC 20402-0001 


\section{FOREWORD}

This publication documents standardized test procedures that can produce valid and reproducible mechanical-property data for lead-free solders. Such data speeds the application of lead-free solders in high-volume, automated production of electronic assemblies, especially when current production expectations combine high levels of quality with the lowest cost. Use of standardized procedures facilitates the comparison of data between laboratories and permits the combination of data from different sources into a single, comprehensive database.

Most dimensions and temperatures are listed without tolerances. Unless otherwise specified, use $\pm 5 \%$ on dimensions, times, and pressures, and $\pm 3^{\circ} \mathrm{C}$ for temperatures.

Many of the procedures assume some skill in the arts of specimen production and testing. Various textbooks and industry brochures (some listed in the Bibliography) can provide background information on these skills and any hazards associated with these procedures.

\section{Solder Database}

Various researchers have already generated useful data; often with procedures similar to those listed above. These data have been collected and are available on the web at www.boulder.nist.gov/div853/. If you have data to offer, please send it to Tom Siewert at siewert@boulder.nist.gov. 



\section{ACKNOWLEDGMENTS}

A primary source of test methods in this document is the 1998 NCMS

Lead-Free Solder Project CDROM (available from NCMS). Members of the NEMI Task Force on Lead-Free Assembly participated in the review and refinement of these procedures. 



\section{TABLE OF CONTENTS}

Solder Database ............................................................................ ii

List of Figures ....................................................................................... viii

Introduction ........................................................................................... 1

0.0 Materials and Processing Details............................................ 3

1.0 Thermal Analysis .................................................................... 4

$2.0 \quad$ Wetting Balance Test .............................................................. 5

3.0 Tensile Specimen Fabrication .............................................6 6

4.0 Tensile Test Procedure ........................................................... 8

5.0 Creep Test Procedure ............................................................

6.0 Metallography .................................................................. 10

7.0 Measurement of Solid State Intermetallic Compound Growth Rate (by dip method) .......................... 11

8.0 Measurement of Liquid-State Intermetallic Compound Growth Rate (by the hot plate method) ............ 14

9.0 Fracture Toughness

10.0 Thermomechanical Fatigue Testing Simulated Solder Joints

11.0 Thermomechanical Fatigue Test Using PWB Test Vehicles .........................................................................................21

12.0 Thermomechanical Fatigue Test Using Strips ....................22

13.0 Liquid Solder Dissolution ......................................................223

14.0 Acoustic Measurements of Elastic Constants ....................26

15.0 Ring-and-Plug Test ...........................................................2 27

16.0 Stress-Rupture Test ............................................................29

17.0 Constitutive Behavior ........................................................... 30

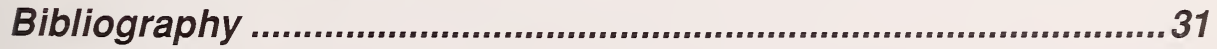




\section{List of Figures}

Figure 1. A typical lead-free solder joint structure after reflow. This SEM micrograph (1800x) shows the (Ni,Cu)-Sn intermetallic reaction layer between $\mathrm{Ni}$ and solder and $\mathrm{Ag}-\mathrm{Sn}$ intermetallic rods crystallized from $\mathrm{Sn}-\mathrm{Ag}-\mathrm{Cu}$ solder. Include a magnification marker on the image, so the magnification calibration does not change with enlargement in printing. 


\section{INTRODUCTION}

Around the world, electronics manufacturers are considering using alternatives to the traditional lead-containing solder alloys. Unfortunately, there are much less data available for most of these lead-free alloys, and what data exist have often been generated with a variety of procedures. Thus, laboratories continue to develop the mechanical-property data needed by their customers; sometimes having to replicate the experiments of others because of differences in procedures. The continual development of new solder fluxes and processing technology also drives the production of additional data. Broad adoption of standard procedures could greatly reduce the number of experiments that would otherwise have to be performed.

The procedures described in this publication have been shown to produce data that are applicable to the design and control of high-volume, automated production of electronic assemblies. Use of standardized procedures facilitates the comparison of data among laboratories and permits the compilation of data from different sources into a single, comprehensive database.

The following pages describe the wide variety of mechanical property tests that were selected for this collection, then refined, by the NEMI Task Groups on Lead-free Alloys and Reliability. Use as many of the tests as needed for your application. When you perform any of these tests, record as much information as possible. In the Foreword, we include a link to some data that have already been generated and entered into a prototype public database. Additional data are welcome. 



\subsection{Materials and Processing Details}

Unique identifiers to be reported for the following tests.

\subsection{Source of Materials}

Batch or lot identification (substrate, solder and flux, as appropriate).

\subsection{Specimen Identification}

Type, orientation, dimensions.

\subsection{Composition}

Major elements, any information on trace elements; analysis method.

\subsection{Flux (if used)}

Standard type (e.g., standard activated rosin flux described in ANSI/IPC/EIA Standard J-STD-002B), composition or product ID.

\subsection{Substrate (if used)}

Part number, structure, thickness of layers, purity, plate or wrought, etc. 


\subsection{Thermal Analysis}

Evaluate melting and solidification temperatures.

\subsection{Equipment}

Differential Scanning Calorimeter (DSC) or Differential Thermal Analyzer (DTA).

\subsection{Specimens}

About $10 \mathrm{mg}$.

\subsection{Parameters}

Ramp rate: $5.0^{\circ} \mathrm{C} / \mathrm{min}$;

Scan: (Scan 3 times, but discard the first scan);

Nitrogen purge.

\subsection{Evaluation}

Measure peak and onset temperatures of each peak through both heating and cooling.

Note: The $5.0^{\circ} \mathrm{C} / \mathrm{min}$ cooling rate allows accurate measurement of the melting and solidification temperatures of these alloys, but this cooling rate is too slow to produce a representative microstructure. DSC or DTA can also be used for study of undercooling at the higher cooling rates $\left(50^{\circ} \mathrm{C} /\right.$ $\min$ to $120^{\circ} \mathrm{C} / \mathrm{min}$ ) that more accurately represent the behavior of actual small-scale solder joints. Collect data in a manner similar to that for melting points. 


\subsection{Wetting Balance Test}

Evaluate wetting behavior of solders and component leads.

\subsection{Equipment}

Commercial wetting balance tester or equivalent.

\subsection{Specimens}

The type of specimens depends on whether the solder and flux combination is to be evaluated and compared with other combinations, or whether component leads with different surface finishes are to be evaluated for a fixed solder/flux combination. In the NCMS project, various lead-free solders were compared using easily-solderable copper wires. (Oxygen-free high-conductivity (OFHC) bare copper wire was used, $25 \mathrm{~mm}$ long ( $1 \mathrm{in}$.), and $0.5 \mathrm{~mm}$ in diameter ( $0.02 \mathrm{in}$., 24 gauge).) For testing of various component leads with different surface finishes, test the specimens with a fixed solder/flux combination as specified by J-STD-002 with the solder temperature as specified in Section 2.4.1.

\subsection{Clean}

Clean the OFHC copper wires per Section 3.2.4 of J-STD-002. Store the specimen in anhydrous alcohol to prevent further oxidation prior to use.

\subsection{Wetting Balance Test}

(Per Sections 4.3.1 or 4.3.2 of J-STD-002.)

\subsubsection{Test Temperatures}

Two temperatures are suggested: (1) Liquidus $+50^{\circ} \mathrm{C}$ (test temperature in J-STD-002 for tin-lead eutectic is $\sim 50^{\circ} \mathrm{C}$ higher than its eutectic temperature); (2) Liquidus $+30^{\circ} \mathrm{C}$ (to be closer to actual practice for lead-free alloys with most processes). (Both temperatures allow reasonable evaluation of the different assembly processes.)

Note: This procedure can also be used to study the wetting characteristics of surfaces other than OFHC copper. 


\subsection{Tensile Specimen Fabrication}

The specimen preparation procedures are intended to duplicate the structure (grain size and orientation) in the actual solder joints. Thus, specimens that are larger than joints should be cooled more rapidly to obtain equivalent properties. Measurements of microstructure, microhardness, and crystallographic texture measurements help to establish this equivalence.

\subsection{Uniaxial (Bulk Solder) Tensile Specimens}

\subsubsection{Dimensions}

Gauge Length $=31.8 \mathrm{~mm}(1.250 \pm 0.005 \mathrm{in}$.$) ;$

Diameter $=3.81 \mathrm{~mm}(0.150 \pm 0.005 \mathrm{in}$. $)$.

\subsubsection{Procedure}

3.1.2.1 Preheat molds (aluminum molds for $\mathrm{Sn}$-Bi alloys to enhance casting properties and no mold release needed; titanium molds for high tin alloys with graphite powder as a lubricant) to $150^{\circ} \mathrm{C}$ above liquidus temperature of alloy.

3.1.2.2 Maintain solder melt at $100^{\circ} \mathrm{C}$ above liquidus temperature with argon shield over liquid solder to reduce dross buildup. The argon flow should be very slow to avoid agitation.

3.1.2.3 Allow $20 \mathrm{~s}$ between removing molds from oven and pouring the cast (bottom fill). Stir the melt immediately prior to pouring. Pour slowly and continuously until solder reaches top of mold, 5-7 s pour time. Do not allow bridging between bars at top of mold.

3.1.2.4 Immediately after pouring, quench molds in tap water by controlled filling of quench tank. Water should fill tank in $60 \mathrm{~s}$ (using aluminum molds) for complete solder solidification. Consider using an intermediate tier in the quench tank to allow for a $10 \mathrm{~s}$ water level dwell at the mold midpoint during filling. Run water until molds are completely cooled, and remove castings from mold. 
3.1.2.5 Typical post-solidification aging: Anneal castings for $16 \mathrm{~h}$ at a temperature two-thirds of the alloy's solidus temperature. Report hardness data or other unusual characteristics of the specimens (e.g., microstructure). Allow $24 \mathrm{~h}$ at room temperature for stress relief before performing tests.

\subsection{Lap Shear Specimens}

\subsubsection{Materials and Dimensions}

Lap shear bar material: AISI type 1045 carbon steel with $0.0127 \mathrm{~mm}$ $\mathrm{Cu}$ or Ni plating. Solder joint volume: 6.4 x $3.2 \times 0.13 \mathrm{~mm}$ (width $\mathrm{x}$ length $\mathrm{x}$ thickness).

\subsubsection{Procedure}

3.2.2.1 Pre-tin joint ends of lap shear bars with solder alloy. Clean with alcohol.

3.2.2.2 Flux the pre-tinned ends with a standard activated rosin flux (such as that listed in J-STD-002B), and align lap shear bars in a spring-loaded fixture to maintain about a $0.013 \mathrm{~mm}(0.0005 \mathrm{in}$.) joint gap during soldering.

3.2.2.3 Use electric hot tweezers to heat joint area to reflow temperature (operation time 5-7 s).

3.2.2.4 Feed new solder into joint from one side to minimize voids in joint. Allow to cool, and remove from fixture.

3.2.2.5 Remove solder joint fillets using a fine jeweler's file.

3.2.2.6 Typical post-solidification aging: Anneal for $16 \mathrm{~h}$ at a temperature near two-thirds of the alloy's solidus temperature, and temper $24 \mathrm{~h}$ at room temperature for stress relief before performing tests. 


\subsection{Tensile Test Procedure}

\subsection{Procedure}

Follow ASTM procedure E8.

\subsection{Specimens}

Tensile bar: per Section 3.1; Lap shear: per Section 3.2.

\subsection{Test Parameters}

Crosshead speed: To achieve strain rates between $10^{-3} / \mathrm{s}$ and $10^{-4} / \mathrm{s}$, although the full range of $10^{-6} / \mathrm{s}$ (creep) to $10^{-2} / \mathrm{s}$ is of interest. Temperatures: -50 to $150^{\circ} \mathrm{C}$, in $25^{\circ} \mathrm{C}$ steps ( 9 tests).

\subsection{Evaluation}

Measure strain with an extensometer; continue up to $20 \%$ before stopping. Discontinue test if the load drops below $\sim 2 \mathrm{~kg}$. Measure load as a function of displacement. Report elastic modulus, $0.2 \%$ offset yield stress, ultimate tensile stress, uniform elongation, total elongation, strength coefficient, and work hardening exponent. 


\subsection{Creep Test Procedure}

\subsection{Procedure}

Follow ASTM procedure E139.

\subsection{Specimens}

Butt joint.

\subsection{Test Parameters}

The strain rate can be $10^{-7} / \mathrm{s}$. Also, the loading can be stopped occasionally to monitor the strain decrease as the load drops to zero, developing on a single specimen, data for a range of creep rates. Temperatures: -50 to $150^{\circ} \mathrm{C}$, in $25^{\circ} \mathrm{C}$ steps ( 9 tests).

\subsection{Evaluation and Reporting}

Measure strain as a function of time. Calculate the strain rate. 


\subsection{Metallography}

Examination of microstructures including different phases in solder and along interfaces.

\subsection{Mount}

Mount the specimen on edge in epoxy. Use a slow-hardening mounting material (such as Buehler Epoxide Resin with separate hardener) to prevent the mount from pulling away from the specimen. Pull a vacuum for the first five minutes that the mounting material is hardening. Release vacuum, and allow 6-8 hours for the mount to cure fully. Use disposable mounts which are glued together.

\subsection{Grinding}

Follow the sequence of 240/400/600 grit paper (600 grit is soft on top, not like the coarser grits). Do not use grit coarser than 240. Spend no more than 2 minutes on each step. Run the wheel at 200-250 rpm.

\subsection{Polishing}

Follow the media size sequence, $15 \mu \mathrm{m} / 6 \mu \mathrm{m} / 1 \mu \mathrm{m} / 0.25 \mu \mathrm{m}$, starting with diamond suspension (such as Buehler Metadi Supreme), which is water based and comes in spray bottles. Use with appropriate polishing wheel preparation, such as Buehler Met Grip liners (thicker w/sticky backing). With $15 \mu \mathrm{m}$ to $6 \mu \mathrm{m}$ grit, use Texmet 1000 hand cloth. With $1 \mu \mathrm{m}$ to $0.25 \mu \mathrm{m}$, use Microcloth (thicker nap). Then, use colloidal silica on microcloth. Spend no more than 2 minutes on each step. Run the wheel at $300 \mathrm{rpm}$.

\subsection{Etching}

Appropriate for alloy. Etching of the specimen in a colloidal suspension of silica is often used. Also, consider a mixture of $10 \% \mathrm{HCl}$ in methanol for a few seconds to reveal the microstructure of most lead-free alloys, and a mixture of 4 parts glycerol, 1 part acetic acid, and 1 part nitric acid at $80^{\circ} \mathrm{C}$ to reveal the intermetallic surface.

\subsection{Photomicrographs}

Magnification of approximately $320 \mathrm{x}$ for microstructure and 1000 to 1600x (air or oil immersion with optical microscope, or higher with a SEM) for intermetallic compounds. Use scanning electron microscopy/ energy dispersive microscopy, as required, to identify intermetallic compounds or phases. 


\subsection{Measurement of Solid State Intermetallic Compound Growth Rate (by dip method)}

\subsection{Equipment}

One or more air furnaces having a maximum temperature of at least $250^{\circ} \mathrm{C}$, controllable to $\pm 1^{\circ} \mathrm{C}$.

\subsection{Substrates}

Metal substrates, such as copper, nickel, or palladium.

\subsubsection{Copper Substrate}

Try polished, OFHC copper sheets with solder coating $(6.4$ x 6.4 x $1.6 \mathrm{~mm})$.

\subsubsection{Coated Substrates}

Coated substrates such as $\mathrm{Au}+\mathrm{Ni}$ over Fe-Ni-Co alloy $\left(\operatorname{Kovar}^{\mathrm{TM}}\right)$ as well as $\mathrm{Pd}, \mathrm{Ni}+\mathrm{Pd}$, or $\mathrm{Ni}+\mathrm{Pd}+\mathrm{Au}$ over $\mathrm{Fe}-\mathrm{Ni}-\mathrm{Co}$ or $\mathrm{Cu}$ substrates could be used. Starting thicknesses of the substrate and various coatings must be established prior to testing.

\subsection{Solders}

Solder should be kept in a pot with a minimum volume of $60 \mathrm{cc}$. Maintain the solder pot temperature at $40^{\circ} \mathrm{C}$ greater than the liquidus temperature of the alloy.

\subsection{Specimen Fabrication Procedure}

7.4.1 Coat the optically-polished side of the specimen with a flux that provides suitable wetting.

7.4.2 Immerse the tab into the solder edge-on with the polished surface on the bottom.

7.4.3 Immerse the specimen in the bath for $5 \mathrm{~s}$.

7.4.4 Remove the specimen from the solder bath by maintaining the bottom, polished surface parallel to the surface of the bath. 
7.4.5 Allow the specimen to cool.

7.4.6 Remove the flux residues by a suitable cleaning process.

\subsection{Thermal Aging Procedures}

7.5.1 Thermal aging is used to accelerate the solid-state growth of the reaction (intermetallic compound) layer between the solder and the substrate or solderable finish. Measurements are reported in terms of thickness and intermetallic growth rate as functions of time, temperature, and composition.

7.5.2 Aging temperature to be used per each of the solder compositions, per aging times of $0,10,40$, and 100 days, are listed below. Care must be taken not to exceed the solidus temperature of the solder composition.

\begin{tabular}{lc}
\hline Alloy Composition & Aging Temperatures $\left({ }^{\circ} \mathrm{C}\right)$ \\
\hline $100 \mathrm{Sn}$ & $135,170,205$ \\
$96 \mathrm{Sn}-4 \mathrm{Cu}$ & $135,170,205$ \\
$95 \mathrm{Sn}-5 \mathrm{In}$ & $135,170,205$ \\
$95 \mathrm{Sn}-5 \mathrm{Bi}$ & $135,170,205$ \\
$91 \mathrm{Sn}-4 \mathrm{Cu}-5 \mathrm{In}$ & $135,170,205$ \\
$90 \mathrm{Sn}-5 \mathrm{In}-5 \mathrm{Bi}$ & $100,135,170$ \\
$91 \mathrm{Sn}-4 \mathrm{Cu}-5 \mathrm{Bi}$ & $135,170,205$ \\
$93 \mathrm{Sn}-2 \mathrm{Cu}-2.5 \mathrm{Bi}-2.5 \mathrm{In}$ & $135,170,205$ \\
86Sn-4Cu-5In-5Bi & $100,135,170$ \\
76Sn-4Cu-10In-10Bi & $100,135,170$ \\
\hline
\end{tabular}

\subsection{Data Analysis}

7.6.1 An optical or SEM micrograph should be taken of the intermetallic compound layer at each of four different locations along the solder/substrate interface, using a minimum magnification of $1000 \mathrm{x}$ (1600 to 2000x is optimal). Because thickness measurements will be determined from these micrographs, a magnification calibration should be provided with each set of data. Figure 1 shows a representative micrograph. 


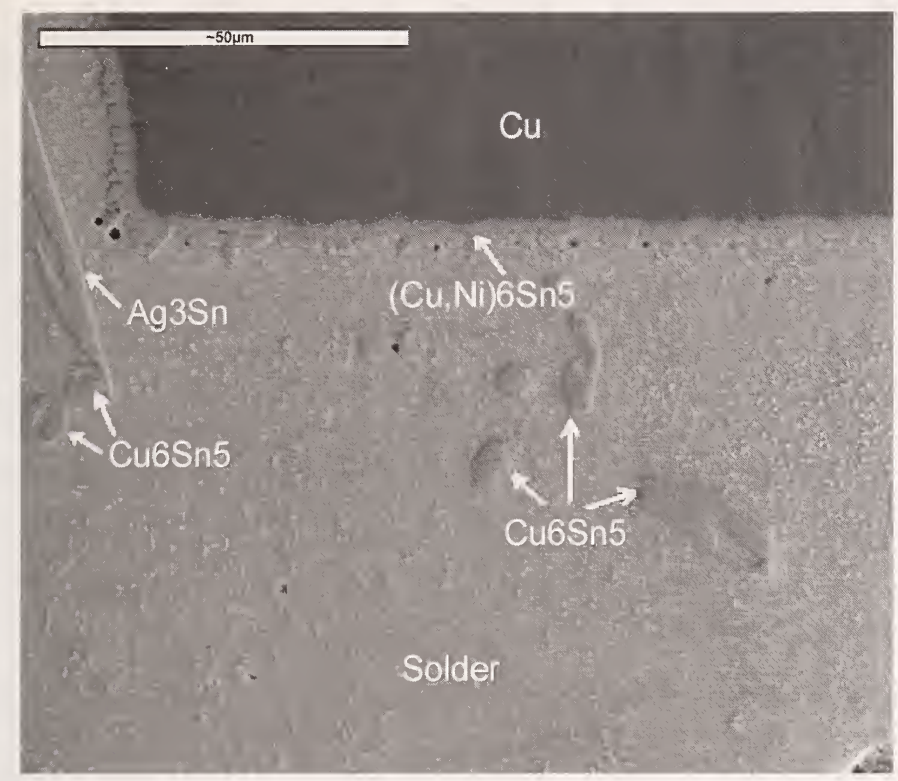

Figure 1. A typical lead-free solder joint structure after reflow. This SEM micrograph (1800x) shows the (Ni,Cu)-Sn intermetallic reaction layer between $\mathrm{Ni}$ and solder and $\mathrm{Ag}-\mathrm{Sn}$ intermetallic rods crystallized from $\mathrm{Sn}-\mathrm{Ag}$-Cu solder. Include a magnification marker on the image, so the magnification calibration does not change with enlargement in printing.

7.6.2 Measure and report the thickness of the intermetallic compound layer at about ten equally-spaced positions along the interface (less for a very uniform layer; as many as 40 for a layer with very uneven thickness). Should more than one layer be present, measure the total layer thickness as well as the thickness of each layer. 


\subsection{Measurement of Liquid-State Intermetallic Compound Growth Rate (by the hot plate method)}

\subsection{Equipment}

Programmable hot plate with a maximum temperature setting of at least $300^{\circ} \mathrm{C}$.

\subsection{Substrates}

Metal substrates, such as copper, nickel, palladium. Dimensions need to be established prior to reflow (i.e., $10 \times 5 \times 1 \mathrm{~mm}$ ).

\subsubsection{Copper Substrate}

Try polished OFHC sheets.

\subsubsection{Coated Substrates}

Coated substrates such as $\mathrm{Au}+\mathrm{Ni}$ over Fe-Ni-Co alloy $\left(\right.$ Kovar $\left.^{\mathrm{TM}}\right)$ as well as $\mathrm{Pd}, \mathrm{Ni}+\mathrm{Pd}$, or $\mathrm{Ni}+\mathrm{Pd}+\mathrm{Au}$ over $\mathrm{Fe}-\mathrm{Ni}-\mathrm{Co}$ or $\mathrm{Cu}$ substrates could be used. Starting thicknesses of the substrate and various coatings must be established prior to testing.

\subsection{Solders}

Solder to be provided in paste form, with $50 \%$ of volume being flux.

\subsection{Flux}

Activated rosin flux per J-STD-002.

\subsection{Specimen Fabrication Procedure}

8.5.1 Preheat the hot plate to the desired reflow temperature; reflow temperatures of $10^{\circ} \mathrm{C}, 20^{\circ} \mathrm{C}, 30^{\circ} \mathrm{C}$, and $40^{\circ} \mathrm{C}$ above melting point or liquidus of solders are preferred.

8.5.2 Monitor temperature with a dummy specimen equipped with a fine-gage Type $\mathrm{K}$ thermocouple. 
8.5.3 Place the substrate on the hot plate once the hot plate reaches the reflow temperature.

8.5.4 Apply a drop of flux to break-up the oxide layer, and wait $30 \mathrm{~s}$ for the substrate to equilibrate to the hot plate temperature. Record temperature of the dummy specimen using the thermocouple.

8.5.5 Apply known amount of solder paste (same ratio of substrate surface to solder volume for constant thickness).

8.5.6 Start is the time at which melting occurs. (Monitoring the thermocouple in the dummy specimen will also provide the start time).

8.5.7 Specimens are removed from the hot plate at specified times (i.e., $20 \mathrm{~s}$, $40 \mathrm{~s}, 60 \mathrm{~s}, 2 \mathrm{~min}, 4 \mathrm{~min}, 8 \mathrm{~min}$ ) and quenched on an iron block or similar media.

8.5.8 Mount and polish the sample to reveal the intermetallic layer.

\subsection{Data Analysis}

8.6.1 An optical or SEM micrograph is taken of the intermetallic compound layer at each of four different locations along the solder/substrate interface, using a nominal magnification of 1600 to 2000x. Because thickness measurements will be determined from these micrographs, a magnification calibration should be provided with each set of data.

8.6.2 Measure the intermetallic compound layer thickness at ten equally-spaced positions along the interface. Should more than one layer be present, measure the total layer thickness as well as the thickness of each layer. A total of 40 data points shall be obtained for the intermetallic compound layer thickness for each aging condition.

8.6.3 Plot time versus total intermetallic layer thickness for each reflow temperature. 
8.6.4 Fit the data to the equation $x(t, T)=k^{n}$, where $k=k_{0} \exp (-Q / R T)$, using regression.

8.6.5 Refit the data to the average value of $\mathrm{n}$ and obtain $\mathrm{k}$ for each temperature.

8.6.6 Arrehenius plot of $\mathrm{k}$ values (ln k vs. 1/T) provide the pre-exponential constant $\mathrm{k}_{\mathrm{o}}$ and apparent activation energy $\mathrm{Q}$. 


\subsection{Fracture Toughness}

\subsection{Equipment}

A materials testing machine equipped with a load cell range near $200 \mathrm{~kg}$.

\subsection{Specimens}

A modified compact-tension specimen with a solder joint between two machined brass halves plated with sufficient $\mathrm{Cu}(10.2 \mu \mathrm{m})$ to withstand reflow and aging conditions. Specimen dimensions are: approximately $32 \mathrm{~mm}$ long, $13 \mathrm{~mm}$ high, and $10 \mathrm{~mm}$ thick with the holes $25 \mathrm{~mm}$ from the back of the specimen and $5.7 \mathrm{~mm}$ from the bottom.

9.2.1 Mask each half of the specimen except the surface to be soldered.

9.2.2 Coat the surface with a standard activated flux, and immerse it into a pot of the appropriate solder at a temperature $40^{\circ} \mathrm{C}$ above the liquidus point to allow the formation of a solder coating of approximately $0.02 \mathrm{~mm}$ thick on each half.

9.2.3 Clamp the two halves together with an aluminum shim at the mouth of the specimen to control the joint separation to $0.25 \mathrm{~mm}$, and then recoat the joint surfaces with flux.

9.2.4 Slowly immerse the clamped assembly into the molten solder.

9.2.5 Remove the specimen from the solder after capillary action fills the joint (confirmed by flux being forced out the top of the specimen, but no more than $30 \mathrm{~s}$ ), and then allow to cool to room temperature.

9.2.6 Remove the clamp and spacer. Polish one side of the specimen to a $1 \mu \mathrm{m}$ finish using standard metallographic techniques; then lightly etch and polish in a colloidal suspension of silica. This polishing technique will confirm the thickness of the intermetallic layers and allow post-test observation of crack location. 


\subsection{Test Procedures and Parameters}

9.3.1 Place the specimen into the load frame by inserting pins through the specimen and corresponding holes in the grips.

9.3.2 Perform the tests at a displacement rate of $2.1 \times 10^{-3} \mathrm{~mm} / \mathrm{s}$. Use a high-resolution load cell ( $200 \mathrm{~kg}$ capacity).

9.3.3 Record data through analog plots of load versus displacement (from stroke motion of the load frame).

\subsection{Evaluation}

9.4.1 Quantify and analyze the fracture toughness as the value $\mathrm{K}_{\mathrm{Q}}$ (the energy required to initiate a crack) per ASTM E399. (This assumes that the results can be characterized by linear elastic fracture mechanics and recognizes that E399 is intended for only monolithic materials. Still, the results are useful for comparison of joints containing different solder alloys.) The apparent fracture toughness is related to the fracture load and the geometry of the specimen:

$$
\text { Where: } K_{Q}=\frac{P}{B W^{1 / 2}} \bullet f\left(\frac{a}{W}\right)
$$

$\mathrm{P}=$ load at fracture $(\mathrm{kN})$

$\mathrm{B}=$ specimen thickness $(0.95 \mathrm{~cm})$

$\mathrm{W}=$ specimen width $(2.54 \mathrm{~cm})$

$\mathrm{a}=$ crack length $(1.74 \mathrm{~cm})$

$\mathrm{f}(\mathrm{a} / \mathrm{w})=$ geometric factor $(5.84)$.

9.4.2 Perform optical and SEM analyses on the cross section of the joint and the fracture surfaces, respectively. Report the elemental composition of the fracture surfaces in the SEM using energy dispersive $\mathrm{X}$-ray analysis and the void fraction in the solder joint (from image analysis of macrophotos of the fracture surface). 


\subsection{Thermomechanical Fatigue Testing - Simulated Solder Joints}

\subsection{Equipment}

A servohydraulic $50 \mathrm{kN}$ (10 kip) loadframe equipped with a $250 \mathrm{~kg}$ (500 lb) load cell and a thermal cycling device capable of cycling temperatures from -80 to $260^{\circ} \mathrm{C}$ are required. Displacements are measured with an extensometer. A computer controls all components of the test and digital data collection including test-frame control electronics. Compressed air is sent through the refrigeration unit, cooled to $-80^{\circ} \mathrm{C}$, and then heated to the required temperature by resistive heating coils in the arm of the equipment. (Cooling the air first reduces the relative humidity.) The cooled and reheated air is then directed to the test specimen in the region of the solder joint. Temperature is monitored by a thermocouple immediately adjacent to the specimen. The equipment is controlled by an IEEE interface between the computer and the equipment. A knife-edge extensometer is attached to the specimen across the region containing the joints. The load frame is run in strain control and the extensometer can measure, and control, the imposed strain. The expansion and/or contraction of the specimen can be accounted for by thermally cycling the specimen with only the extensometer attached over the test temperature range. The $10 \%$ strain can then be added to the expansion/contraction of the specimen to ensure that $10 \%$ strain is imposed on the specimen. The extent of TMF is monitored by the load drop measured across the joints.

\subsection{Specimens}

The specimens are made from three Al boards having 9 solder joints per side defined by machining and $\mathrm{Cu}$ electroplating techniques. When assembled, the ends of the specimen are gripped and strain is imposed along the axis of the specimen resulting in shear strain in each of the joints.

10.2.1 Pre-tin the copper lands with the appropriate solder alloy.

10.2.2 Weigh out enough solder alloy to make joints that would have a cylindrical shape $0.25 \mathrm{~mm}$ (0.010 in.) thick over the joint footprint.

10.2.3 Reflow the specimen in air, with an RMA flux, at temperatures $40^{\circ} \mathrm{C}$ above the melting point or liquidus of the solder alloy. 


\subsection{Test Parameters}

10.3.1 Temperature ranges for high-Sn lead-free solders, depending on application: $-55^{\circ}$ to $150^{\circ} \mathrm{C},-55^{\circ}$ to $125^{\circ} \mathrm{C},-40^{\circ}$ to $125^{\circ} \mathrm{C}$, or $0^{\circ}$ to $100^{\circ} \mathrm{C}$; $\left(-55^{\circ}\right.$ to $90^{\circ} \mathrm{C},-40^{\circ}$ to $100^{\circ} \mathrm{C}$, or $0^{\circ}$ to $100^{\circ} \mathrm{C}$ for lower temperature alloys such as $\mathrm{Sn}-58 \mathrm{Bi})$.

10.3.2 Pre-strain: $10 \%$.

10.3.3 The temperature/strain profile should follow a ramped wave with hold times at the temperature/strain extremes. The hold times should be 3 minutes at each extreme with a deformation rate of $2.9 \times 10^{-4} / \mathrm{s}$ from one temperature extreme to another.

10.3.4 Data collection: It is useful to collect data on the resultant load, temperature, strain applied, and the voltage across the joints. The data should be collected and stored every $5 \mathrm{~s}$ during the cycle.

\subsection{Evaluation}

10.4.1 Plot hysteresis loops using the strain (or temperature) and the resultant load for each cycle. The mechanical data collected during the test can be described as a hysteresis loop during each cycle as a plot of strain (or temperature) versus the resultant load. The data on this plot can be described and summarized as: the maximum load on the high-temperature portion of the cycle (high load), the minimum load on the low-temperature portion (low load), and the load to which the specimen relaxes during the high-temperature hold portion of the cycle (relax load). (No load relaxation was observed during the low-temperature portion of the cycle.)

\subsubsection{Metallography}

10.4.2.1 Section the specimen and mount in epoxy.

10.4.2.2 Grind and polish down to a $10 \mu \mathrm{m}$ diamond finish.

10.4.2.3 Etch the specimen in a colloidal suspension of silica. 
11.0 Thermomechanical Fatigue Test Using PWB Test Vehicles

Follow the procedures in the latest version of IPC-9701. 


\subsection{Thermomechanical Fatigue Test Using Strips}

This section is based on a paper by Pao, et al. See the reference in the bibliography for more details.

\subsection{Test Specimen}

2 long strips (beams of the material couple of interest), joined by solder at the ends. Aluminum and aluminum oxide (a CTE mismatch of $14 \mathrm{ppm} /{ }^{\circ} \mathrm{C}$ ) were used in the paper to introduce large strains, but common materials used in electronics manufacturing might also be evaluated.

\subsection{Equipment}

\subsubsection{Strain Gages}

Four high-temperature strain gages are mounted on the specimen faces to measure the strains that occur during thermal cycling.

\subsubsection{Wheatstone Bridge}

A high-resolution bridge is used to improve the sensitivity to $20 \mu \in /$ $\mathrm{MPa}$. The beam geometry, together with the high resolution bridge, permits detection of stresses as low as $0.5 \mathrm{MPa}$ in the specimens.

\subsubsection{Thermal Cycling Chamber}

Use a chamber capable of spanning the range of interest with appropriate ramp rates. During thermal cycling, the CTE mismatch between the two beams will introduce bending stresses.

\subsection{Analysis}

Calibrate the strain gages per the recommended procedure. Use the equations in the paper by Pao to convert from strain in the beams to stress in the solder. After the test, the specimen can be sectioned to confirm the dimensions and to check for cracks. The data can then be plotted and reported in conventional creep formats. 


\subsection{Liquid Solder Dissolution}

Experiments to determine the extent of dissolution of a substrate by molten solder.

\subsection{Equipment}

Two solder baths with a capacity of $1 \mathrm{~kg}(2 \mathrm{lb})$ each. Digital imageanalysis system to measure changes in the substrate thickness.

\subsection{Specimens}

\subsubsection{Specimen Materials}

Metal substrates, such as copper, nickel, palladium.

\subsubsection{Copper Substrate}

Polished, oxygen-free, high-conductivity copper (OFHC) sheets.

\subsubsection{Coated Substrates}

Coated substrates such as $\mathrm{Au}+\mathrm{Ni}$ over Fe-Ni-Co alloy (Kovar ${ }^{\mathrm{TM}}$ ) as well as $\mathrm{Ag}, \mathrm{Pd}, \mathrm{Ni}+\mathrm{Pd}$, or $\mathrm{Ni}+\mathrm{Pd}+\mathrm{Au}$ over $\mathrm{Fe}-\mathrm{Ni}-\mathrm{Co}$ or $\mathrm{Cu}$ substrates could be used. Starting thicknesses of the substrate and various coatings must be established prior to testing.

\subsubsection{Specimen Shape}

13.2.2.1 Planar coupons measuring approximately 6.4 x 6.4 x $1.6 \mathrm{~mm}$ are used for the tests.

13.2.2.2 Cylindrical specimens of wire, $0.68 \mathrm{~mm}$ (0.031 in.) in diameter.

\subsubsection{Specimen Preparation}

13.2.3.1 Degrease the substrates in trichloroethane (or equivalent), etch in a 1:1 solution of $\mathrm{HCl}$ and water for $30 \mathrm{~s}$, rinse to remove any acid residues, and dry. 
13.2.3.2 Wrap the plate and wire specimens around their respective perimeters with Kapton ${ }^{\mathrm{TM}}$ tape, leaving a $12 \mathrm{~mm}$ (0.5 in.) wide surface "band" around the specimen, extending from the bottom edge.

13.2.3.3 Coat the exposed regions of the plate and wire specimens with a rosin-based, mildly-activated flux.

\subsubsection{Solders}

$$
\begin{aligned}
& \text { Sn-3.9Ag- } 0.6 \mathrm{Cu}\left(\mathrm{T}_{\text {melt }}=217-220^{\circ} \mathrm{C}\right) \text {; } \\
& \mathrm{Sn}-3.5 \mathrm{Ag}\left(\mathrm{T}_{\text {onset }}=221^{\circ} \mathrm{C}\right) \\
& \mathrm{Sn}-0.7 \mathrm{Cu}\left(\mathrm{T}_{\text {eut. }}=227^{\circ} \mathrm{C}\right) \\
& \mathrm{Sn}-37 \mathrm{~Pb}\left(\mathrm{~T}_{\text {eut. }}=183^{\circ} \mathrm{C}\right)
\end{aligned}
$$

\subsection{Test Procedure/Parameters}

The immersion-time parameters are 5, 10, 20, 50, 75, and $100 \mathrm{~s}$; three solder pot temperatures are used per alloy; selected values are shown in the table below.

\begin{tabular}{lccc}
\hline & \multicolumn{3}{c}{ Pot Temperatures $\left({ }^{\circ} \mathbf{C}\right)$} \\
\cline { 2 - 4 } Solders & Pot \#1 & Pot \#2 & Pot \#3 \\
\hline Sn-3.9Ag-0.6Cu & 240 & 255 & 270 \\
Sn-3.5Ag & 240 & 255 & 270 \\
Sn-0.7Cu & 250 & 265 & 280 \\
$63 \mathrm{Sn}-37 \mathrm{~Pb}$ & 205 & 220 & 235 \\
\hline
\end{tabular}

\subsection{Evaluation}

\subsubsection{Thickness Measurement of Plated Specimens}

13.4.1.1 Measure 20 thicknesses on each of the non-immersed and immersed segments of the coupons, and describe the results by a mean (x) and \pm one standard deviation (s) as the error term. 
13.4.1.1.1 Determine the dissolution distance by subtracting the thickness in the immersed area from the original thickness of the plate; then, dividing that value by two (2) so as to represent a single surface.

13.4.1.1.2 Determine the error term for the difference as follows:

(1) A fractional error is defined as $\mathrm{s} / \mathrm{x}$ for each of the data sets from the immersed and non-immersed regions. (2) The fractional errors are added together, the value of which is designated as the "fractional error for the difference." (3) This "fractional error for the difference" is multiplied by the dissolution distance to arrive at the \pm error term. (4) The two data sets per each of the time/temperature conditions are combined by combining the immersed plate thickness data from Trial \#1 with the same data from Trial \#2.

13.4.1.2 The same procedure is performed on the plate thickness of the non-immersed regions. The values of $\mathrm{x}$ and $\mathrm{s}$ are computed; the overall dissolution being the difference between the two means of the combined data (divided by 2 to represent one surface).

The error term is computed in the same manner as described above.

\subsubsection{Thickness Measurement of Wire Specimens}

13.4.2.1 Measure the thickness reduction of the wire specimens at eight diametrical positions about the specimen footprint.

13.4.2.2 Use the same procedures for data analysis as outlined above for the plate specimens. 


\subsection{Acoustic Measurements of Elastic Constants}

\subsection{Equipment}

An acoustic microscope.

\subsection{Specimens}

Cast the specimens into a cylindrical shape and machine to final dimensions of $20 \mathrm{~mm}(0.8 \mathrm{in}$. long by $10 \mathrm{~mm}(0.4 \mathrm{in})$.$) in diameter.$

\subsection{Test Procedure/Parameters}

The testing temperatures $23^{\circ} \mathrm{C}$ to $125^{\circ} \mathrm{C}$ with a minimum of 12 testing temperatures between these extremes.

\subsection{Evaluation}

Determine the elastic constants as a function of temperature. 


\subsection{Ring-and-Plug Test}

\subsection{Equipment}

A standard test load frame.

\subsubsection{Test Fixture}

Ring: Inner diameter $=3.175 \mathrm{~mm}(0.125 \mathrm{in}$.);

Outer diameter $=9.525 \mathrm{~mm}(0.375 \mathrm{in}$.);

Thickness $=3.175 \mathrm{~mm}(0.125 \mathrm{in}$.);

Plug: a solid cylinder having a diameter of $2.794 \mathrm{~mm}(0.110 \mathrm{in}$.) and length of $9.525 \mathrm{~mm}(0.375 \mathrm{in}$.), and effective joint gap (the difference between outer diameter of the plug and inner diameter of the ring) is $0.19 \mathrm{~mm}(0.0075 \mathrm{in}$.).

\subsection{Joint Fabrication}

15.2.1 Degrease the $\mathrm{Cu}$ ring and plug by immersing in isopropyl alcohol for 2 min.

15.2.2 Clean in fluoroboric acid (10\% HBF in water) for 5 minutes at room temperature with agitation (use caution in handling; also see IPC-CS-70), rinse twice in distilled or deionized water, insert twice in isopropyl alcohol, and air dry.

15.2.3 Coat with flux, J-STD-004, Type ROL1 (formerly RMA).

15.2.4 Insert the plug into the ring hole accompanied by four $\mathrm{Cu}$ wires of $0.18 \mathrm{~mm}$ (0.007 in.) diameter in order to maintain concentricity between the plug and the ring.

15.2.5 Prepare a preform of the particular solder for testing from a short length of wire by twisting the wire around the plug-ring intersection.

15.2.6 Place the assembled unit onto a stainless steel fixture and, in turn, place it upon a hot plate held at $300^{\circ} \mathrm{C}$. Keep the assembly on the hot plate for a duration of $15 \mathrm{~s}$ past the time at which the solder preform is observed to have melted. 
15.2.7 Remove the assembly from the hot plate and allow to cool.

15.2.8 Cut off the protruding ends of the plug with a slow-speed diamond saw, and polish the two faces flat.

\subsection{Test Procedure/Parameters}

15.3.1 Displacement rate $=10 \mathrm{~mm} / \mathrm{min}$.

15.3.2 Run four tests per solder alloy composition.

\subsection{Evaluation}

Report the maximum load achieved. The results are represented as the mean and plus-or-minus one standard deviation of the four tests. Reference: ITRI Report 656. 


\subsection{Stress-Rupture Test}

\subsection{Test Specimens}

Tensile bar: $31.7 \mathrm{~mm}$ (1.25 in.) gauge length, $3.8 \mathrm{~mm}$ (0.15 in.) diameter; or lap shear: $6.4 \mathrm{~mm} \times 3.175 \mathrm{~mm} \times 0.127 \mathrm{~mm}(0.25$ long $\mathrm{x}$ 0.125 wide $\mathrm{x} 0.005$ in. thick), with AISI type 1045 carbon steel substrate plated with $0.0125 \mathrm{~mm}$ (0.0005 in.) $\mathrm{Cu}$ or $\mathrm{Ni}$.

\subsection{Temperatures}

$-25^{\circ} \mathrm{C}, 25^{\circ} \mathrm{C}, 75^{\circ} \mathrm{C}$, and $125^{\circ} \mathrm{C}$.

\subsection{Initial Stress}

Low-melt alloys: $9 \mathrm{MPa}$ (1250 psi) and $18 \mathrm{MPa}$ (2500 psi); High-melt alloys: $18 \mathrm{MPa}$ (2500 psi) and $35 \mathrm{MPa}$ (5000 psi).

\subsection{Measure}

Measure the time to failure and percent elongation at break. With the assumption that there are no structural changes occurring in the material, the slope of the stress-rupture line will remain constant. So, instead of reporting the data as time to failure at a certain stress (e.g., $18 \mathrm{MPa}$, $2500 \mathrm{psi})$, report the stress to failure at certain times $(10,1,000$, and $10,000 \mathrm{~min}$.) for the comparison of the different solder materials. 


\subsection{Constitutive Behavior}

\subsection{Bulk Solder Specimens}

Fabricate by casting the alloys in a split steel mold. Prior to casting, heat the alloys $40^{\circ} \mathrm{C}$ above their melting point or liquidus, then pour directly into the chilled mold. This will promote the formation of the fine microstructure that is found in the small solder joints used in electronic packages. Cut specimens from the cast ingots, and mount in epoxy for metallographic observation. Hand polish on sequentially finer nylon wheels using diamond paste; follow by polishing by a colloidal suspension of silica on a vibratory polisher.

The mechanical response of the various solder alloys can be determined through a series of isothermal uniaxial compression creep tests. (The specimens can also be tested after isothermal aging to coarsen the microstructures.) For test specimens, use right circular cylinders $10 \mathrm{~mm}$ (0.4 in.) diameter by $20 \mathrm{~mm}(0.8 \mathrm{in}$.) in length. Use a test machine fitted with an environmental chamber and a relatively small (such as $55 \mathrm{kN}$ ) load cell. Test the alloys at $-25^{\circ} \mathrm{C}, 25^{\circ} \mathrm{C}, 75^{\circ} \mathrm{C}$, and $125^{\circ} \mathrm{C}$. Each specimen should be allowed to equilibrate in the environmental chamber for $30 \mathrm{~min}$. prior to testing. A compressive prestrain of approximately one percent should be applied to the specimens to ensure contact between the specimen and the platens. Test in load control with stresses ranging from 10 to $80 \mathrm{MPa}$, applied using a $1 \mathrm{~s}$ linear ramp. Platen displacement should be monitored as a function of time with a digital oscilloscope with data stored on disk.

The ASCII-formatted strain-time data can be plotted to determine the minimum strain rate for each stress and temperature. A plotting program for engineering analysis should be used to fit the data according to the Sherby-Dorn power-law creep equation:

$$
\dot{\varepsilon}=A\left(\sigma^{n} / T\right) \exp (-Q / R T)
$$

Attempts might be made to fit the $\mathrm{Pb}$-free solder alloy data to a sinh power-law equation. In past tests, the near-eutectic $60 \mathrm{Sn}-40 \mathrm{~Pb}$ alloy has shown power-law breakdown at temperatures lower than $20^{\circ} \mathrm{C}$, and these data could be fit with the Garofalo sinh equation. 


\section{Bibliography}

Joint Industry Standard: Guidelines for Chemical Handling Safety in Printed Circuit Board Manufacturing. ANSI/IPC-CS-70. Rev. ed. Northbrook: IPC.

Joint Industry Standard: Solderability Tests for Component Leads, Terminations, Lugs, Terminals and Wires. ANSI/IPC/EIS J-STD-002A. Rev. ed. Arlington: Electronic Industry Alliance or Northbrook: IPC.

Lead Free Solder Project. (A CDROM report.) Ann Arbor: National Center for Manufacturing Sciences, 1999.

"Mechanical Testing and Evaluation." ASM Handbook, Vol. 8, Rev. ed. Materials Park: ASM International.

Pao, Y.-H., et al. "Measurement of Mechanical Behavior of High Lead Lead-Tin Solder Joints Subjected to Thermal Cycling." Journal of Electronic Packaging, 114, June 1992, 135.

Standard Test Method for Conducting Creep, Creep Rupture, and Stress Rupture Tests of Metallic Materials. ASTM E 139. Rev. ed. West Conshohocken: ASTM.

Standard Test Method for Tension Testing of Metallic Materials [Metric]. ASTM E 8M. Rev. ed. West Conshohocken: ASTM. 

8 